\title{
Media and Law
}

\author{
Janet Cotterill
}

Published online: 21 September 2010

(C) Springer Science+Business Media B.V. 2010

This Special Issue of The International Journal for the Semiotics of Law/Revue Internationale de Sémiotique Juridique concentrates on a relatively new and applied area: the application of semiotic methods and approaches to the analysis of media texts with a legal focus.

The legal context in each respective article varies widely, from texts dealing with a single trial to those with national and international status, such as the Constitution of the United States. Duncanson explores its realisation in the Hollywood hit movie The Matrix. She employs a complex multimodal analysis of the movie to show some of the ways in which the values and ideals embodied in the Constitution are represented and re-contextualised for the consumption of a broader, more popular audience.

Gies' context is equally broad in its legal textual origins. His article deals with the European Human Rights Act (1998) and its potentially conflictual representations in the British press. Within a Barthian context, Gies examines the parallel ways in which such values and legal principles are conveyed by governmental and other official sources.

The notions of sovereignty and religion in Israel are explored by Bogoch and Holzman-Gazit. They use data from a Supreme Court decision on Israeli citizenship and its representation in both the 'popular' and 'elite' press to analyze the semiotic complexities of nationhood. This is achieved through the lens of the linguistic, visual and paralinguistic features of the two newspapers.

Cotterill's article also draws on a corpus of print and online newspaper texts. It explores the semiotic realisations of variables such as gender and socio-economic status, as well as physical and behavioural representations of the perpetrator in a case of parental kidnapping. The case, and the individuals concerned, are seen to

\footnotetext{
J. Cotterill ( $\bowtie)$

Centre for Language and Communication Research,

Cardiff University, Cardiff CF10 3EU, UK

e-mail: cotterillj@cf.ac.uk
} 
symbolize 'Broken Britain', a commonly held and highly contentious concept in the contemporary British media.

Chaemsaithong's contribution marks a shift from the contemporary to the historical, studying the construction of the expert witness's identity and power in the discourse of the eighteenth century American courtroom. The notion of 'expertise' is seen as a negotiable construct, and Chaemsaithong's article explores the ways in which attorneys and witnesses of the time both challenged and established the authority of the medical expert witness.

The final article by Le Cheng also deals with the courtroom setting, but moves to an analysis of the impact of current technological modes of communication and information recording and retrieval on courtroom interaction. A discussion of 'intersemiotic translation' from law to media leads onto the inevitable semiotic conflicts brought about by the translation, transcription and interpretation of testimony and judgements. Finally, the reporting and citation of these texts is explored. It is clear that there is considerable potential for both innocuous and hazardous variation in the messages 'translated'.

In summary, this set of articles brings together the media and legal domains and illustrates some of the fascinating results which can come from employing both a verbal and a visual semiotic approach to analysing the data.

Acknowledgments I would personally like to thank the Editor-in-Chief, Dr Anne Wagner, for her considerable assistance and input into this Special Issue. Although my name appears as Guest Editor, Anne was both able and willing to step in on several occasions to take over the editorial process, caused by my own illness. I am extremely grateful for her guidance, her professionalism and most of all her patience in ensuring that this issue made it to press on time, and I want to acknowledge her involvement in the public domain. 